Вдовіченко 0. Значення міста в мовній свідомості жителів...

https://doi.org/10.34142/23129387.2019.61.03

УДК 159.9.018; 81'1, 81'27

ORCID 0000-0002-3553-1106

\title{
ЗНАЧЕНИЯ ГОРОДА В ЯЗЫКОМ СОЗНАНИИ ЖИТЕЛЕЙ (СЕМАНТИЧЕСКАЯ ИНТЕРПРЕТАЦИЯ РЕЗУЛЬТАТОВ ПСИХОЛИНГВИСТИЧЕСКОГО ЭКСПЕРИМЕНТА СО \\ СЛОВОМ «ОДЕССА») \\ Оксана В. Вдовиченко,
}

дочент кафедры теории и методики практической психологии.

Государственное учреждение «Южноукраинский

национальный педагогический университет

имени К.Д. Ушинского», г. Одесса, Украина

E-mail:werta_2i@ukr.net

\section{Значення міста в мовній свідомості жителів (семантична інтерпретація результатів психолінгвістичного експерименту зі словом «Одеса») Оксана В. Вдовіченко,}

дочент кафедри теорії та методики практичної психології,

Державний заклад «Південноукраӥнський начіональний педагогічний університет імені К.Д. Ушинського»,

м. Одеса, Украӥна

Мета дослідження - визначити психолінгвістичне значення кониепту «Одеса» у мовній свідомості ї̈ мешканиів.

Методи $і$ вибірка дослідження. $У$ дослідженні застосовано вільний асоиіативний експеримент. Досліджувані мали написати n'ять асоціацій на слово «Одеса». Усього у роботі взяли участь 117 респондентів, 16-57 років, які постійно проживають у місті Одеса.

Результати. Шляхом застосування частотного аналізу асоціатів на слово-стимул Одеса було проаналізовано найбільш розповсюджені асоціації, які розкривають психолінгвістичне значення концепту «Одеса». Визначено ранги найбільш частих реакцій за всією сукупністю асочіацій та по першій реакції. Проаналізовано семантичні групи асочіатів. Змістовний $і$ кількісний аналіз асоціатів за отриманими групами дозволяе визначити Одесу в мовній 
свідомості ї̈ жителів як морське туристичне місто, що має славну історію, гарну архітектуру $i \in$ символом гумору. Здійснено порівняльний аналіз концепту «Одеса» 3 концептами «Москва» та «Київ».

Висновки. Із результатів семантичної інтерпретаиії концепту «Одеса» слідує, щио ие місто асоціюється з морем, красивою архітектурною і славною історією, що ототожнюеться з юмориною і веселощами. У асоціативному полі даного концепту найбільщу групу асоціатів склали ті, щро описують його зв'язок із природою та морем. Значну групу периферійних та одиничних реакцій склали лексеми, що відносяться до асоціативного полю архітектурної та історичної тематики. На відміну від столичних міст, Одеса не має ознак мегаполісу та центру інфраструктури у мовній картині світу ї̈ городян.

Ключові слова: психолінгвістичний експеримент, конщепт, урбаністична психологія, вільний асоиіативний експеримент, Одеса, психологія городян, мовна картина світу.

\section{Meanings of the city in the lingual awareness of the residents (semantic interpretation of the results of the psycholinguistic experiment with the word "Odesa") Oksana V. Vdovichenko,}

Associate Professor of the Department of Throry and

Methodology of Practical Psychology,

K. D. Ushynsky South Ukrainian National Pedagogical University, Odesa, Ukraine

The Aim of the study is to determine the psycholinguistic meaning of the concept of Odesa in the linguistic consciousness of its inhabitants.

Research Methods and Sample. The study used a free associative experiment. The subjects were to write five associations on the word "Odesa". A total of 117 respondents, aged 16-57, who live in Odesa, participated in the study.

Results. By applying the frequency analysis of associates to the wordstimulus Odessa, the most widespread associations have been analyzed, which reveal the psycholinguistic meaning of the concept "Odessa". Ranks of the most frequent reactions on the whole set of associations and on the first reaction are determined. Semantic groups of associates are analyzed. A meaningful and quantitative analysis of the associates of the resulting semantic groups makes it possible to identify Odesa in the linguistic 
consciousness of its inhabitants as a maritime tourist city that has a glorious history, beautiful architecture and is a symbol of humor. The comparative analysis of the concept "Odesa" with the concepts "Moscow" and "Kiev" is carried out.

Conclusions. From the results of the semantic interpretation of the concept of "Odesa" it follows that this city is associated with the sea, beautiful architectural and glorious history, which is equated with humor and fun. In the associative field of this concept, the largest group of associates was those describing its relationship with nature and the sea. A significant group of peripheral and single reactions consisted of tokens related to the associative field of architectural and historical topics. Unlike metropolitan cities, Odesa has no signs of a metropolis and infrastructure center in the linguistic picture of the world of its citizens.

Keywords: psycholinguistic experiment, concept, urban psychology, free associative experiment, Odesa, psychology of citizens, linguistic picture of the world.

Постановка проблемы. Современные исследования образов территорий, выполненные с применением методов психосемантики и психолингвистики, которые позволяют получить доступ к языковому сознанию, крайне немногочисленны (Киселева, 2009; Колесова, Ганичева, 2016; Тарасов, 2006; Фельде, 2011; Ши Ся, 2008 и др.). В большей степени они касаются изучения образа стран, частей света, регионов (Кондратьева и Фролова, 2018; Киселева, 2009; Кулик, 2012; Петухова, Наумова, 2012; Чесноков, 2003; Ши Ся, 2008), реже - городов (Кудрявцева, 2006; Kudryavtsev, 2019). Соответственно, проблема изучения образов городов, существующих в обыденном языковом сознании горожан, остается открытой.

Цель исследования. Цель работы состоит в том, чтобы на основе прикладного психолингвистического исследования описать психолингвистические значения вербализированного концепта «Одесса».

Методы исследования. Основным методом проведенного исследования был психолингвистический эксперимент, главным этапом которого выступил свободный ассоциативный эксперимент (САЭ) со словом-стимулом «Одесса». 
Дополнительными методами были опрос (с целью уточнения результатов САЭ), анкетирование (для уточнения характеристик выборки). В качестве математико-статистических методов анализа результатов исследования применялись частотный анализ, позволяющий выявить тенденции в распределении ассоциаций.

САЭ со словом-стимулом «Одесса» проводился в письменной форме. Согласно инструкции испытуемые должны указать пол, возраст, образование/ специальность, семейное положение и написать первые пять слов, которые пришли им в голову, с которыми у них ассоциировалось слово «Одесса».

Общее число испытуемых, которые приняли участие в эксперименте, составило 117 (16-57 лет), в равном соотношении мужчин и женщин. Из них по критерию принадлежности к городу Одесса: 65 \% коренных жителей города Одесса, 45\% гости города, приезжие на учебу или работу. В результате анкетирования было выяснено, что все респонденты относят себя к носителям как русского, так и украинского языков.

Результаты. По результатам частотного анализа САЭ на стимул «Одесса» были построены ассоциативные поля по пяти реакциям и по первой реакции. На слово-стимул «Одесса» испытуемые дали 589 реакций (обработка результатов САЭ по пяти реакциям), включая 43 словосочетаний или законченных предложений, реакций с частотой больше 1-71, единичных - 166, отказов 0 , не знают значение слова - 0 . Наиболее высокочастотные ассоциации показаны в таблице 1.

Таблица 1

Частота ассоциаций на слово-стимул «Одесса» по пяти реакциям САЭ

\begin{tabular}{|l|c|c|}
\hline \multicolumn{1}{|c|}{ Ассоциаты } & Абс. & Частот, \% \\
\hline $\begin{array}{l}\text { Море [море 96, Черное море 1, теплое море 1, } \\
\text { яркое солнце и синее море 1] }\end{array}$ & 99 & $16,8 \%$ \\
\hline Солнце [солнце 19, яркое солнце и синееморе 1] & 20 & $3,4 \%$ \\
\hline Юмор [юмор 18, хороший юмор 1, юморина 1] & 20 & $3,4 \%$ \\
\hline Пляж 15 & 15 & $2,5 \%$ \\
\hline Привоз 14 & 14 & $2,4 \%$ \\
\hline Туристы 11 & 11 & $1,9 \%$ \\
\hline Дом 10 & 10 & $1,7 \%$ \\
\hline
\end{tabular}


Вдовіченко 0. Значення міста в мовній свідомості жителів...

При полевой стратификации результатов экспериментальных исследований значения и концепта И.А. Стернин и А.В. Рудакова (2012) предлагают относить ассоциации с частотой более $10 \%$ к ядру поля. В данном случае в зону ядра входит лишь слово «море». Зону поля ближней периферии должны представлять ассоциации с частотой 4-10\%, однако ассоциаций к слову «Одесса» с такой частотой обнаружено не было.

В зону дальней периферии (ассоциации с частотой 2-3\%) входят имена существительные нарицательные и собственные: «солнще» 19 - ранг 2, «юмор» 18 - ранг 3, «пляж» 15 - ранг 4, «Привоз» 14 - ранг 5.

К крайней периферии (ассоциации с частотой менее 2\%) входят все остальные ассоциации, среди которых наибольшую частоту имеют: «туристыл» 11 - ранг 6, «дом» 10 - ранг 8, а также ряд слов с частотой 9, а именно: «архитектура», «Дерибасовская», «отдых».

Затем была проведена частичная семная интерпретация результатов частотного анализа САЭ на стимул «Одесса» по первой реакции. Анализируя данные, полученных после частичной семной интерпретации, изменилась последовательность некоторых высокочастотных ассоциатов периферии (см. табл. 2).

Таблица 2

\section{Частота ассоциаций на слово-стимул «Одесса» по} первой реакции САЭ

\begin{tabular}{|l|c|c|}
\hline \multicolumn{1}{|c|}{ Ассоциаты } & Абс. & Частота, \% \\
\hline Море & 28 & $23,9 \%$ \\
\hline Солнце & 6 & $5,1 \%$ \\
\hline Пляж & 5 & $4,2 \%$ \\
\hline Мама & 4 & $3,4 \%$ \\
\hline Привоз & 3 & $2,6 \%$ \\
\hline Акация & 3 & $2,6 \%$ \\
\hline
\end{tabular}

Лексема «море» по первой реакции имеет большую частоту и занимает первый ранг. Лексема «солнце» по первой реакции, как и по пяти реакциям, заняла второй ранг. Лексема «пляж» 
имеет большую частоту по первой реакции по сравнению с пятью реакциями в целом. Слово «Привоз» сохранило пятый ранг по первой ассоциации. Новым словом в списке наиболее высокочастотных ассоциаций по первой реакции выступила лексема «акация».

Таким образом, первой реакцией на слово «Одесса»у жителей города выступают образные ассоциации, связанные с морем: «море», «солнце», «пляж», а также метафорические по содержанию ассоциации «мама», «Привоз», «акация», связанные с городом Одесса. Например, «Одесса-мама» (устойчивое сочетание, идиома), «Привоз» - символ города, знаковая достопримечательность, «акация» - также образный символ города.

На следующем этапе исследования были осмыслены периферийные и единичные реакции по совокупности всех реакций испытуемых.

Наибольшую группу реакций составили те, которые описывают концепт «Одесса» с помощью существительных, прилагательных и других частей речи для обозначения ее связи с морем и природой: море 96, солнце 18, пляж 15, солнечная 9, якорь 8, тепло 7, чайка 6, песок 4, природа 4, акачия 3, жара 3, корабль 3, маяк 3, морепродукты 3, лето 2, морской вокзал 2, пирс 2, рыба 2, берег 1, ветер 1 ,виноград 1, влажность 1, воздух 1, деревья 1, каштаны 1, курорт 1, набережная 1, пейзажи 1 , портовый город 1 , потрясающие закать и удивительные рассветы 1, причал 1, сирена 1, солнечный город 1, судна 1, теплая 1, теплое море 1, Черное море 1, шаланды полные кефали 1, шум прибоя 1, яркое солнце и синее море 1. Доля описанной выше группы ассоциаций составляет 35,9\% от совокупности всех наблюдаемых ассоциаций.

Значительную группу периферийных и единичных реакций составили лексемы, относящиеся к ассоциативному полю культурно-исторической и архитектурной тематики, а также ассоциации, отражающие достопримечательности города: Привоз 14, дом 10, архитектура 9, Дерибасовская 9, опера 6, Оперный театр 6, 7 км 5, Дюк 5, Аркадия 4, дворики 4, Парк 4, 
дорога 3, брусчатка 2, исторический 2, история 2, красивая архитектура 2, лестниияа 2, Молдаванка 2, Потемкинская лестница 2, город-герой 2, Соборка 2, достопримечательности 1, герой 1, здания 1, Екатерина Вторая 1, катакомбы 1, красивые достопримечательности 1, красивые здания 1, красивый старинный город 1, красивые улиць 1, культура 1, маленькие дворики 1, стиль 1, одесские дворики 1, Оперный 1, памятник Екатерине 1, памятники 1, парк Шевченко 1, поселок Котовского 1, Приморский бульвар 1, старые дворики 1, уютные дворики 1. Доля описанной выше группы ассоциаций составляет $18,9 \%$ от совокупности всех наблюдаемых ассоциаций.

Отдельную группу ассоциаций, преимущественно из прилагательных, представляющую описание города составили следующие реакции: красивая 6, яркая 5, уютная 4, гостеприимная 3, красота 3, многонаииональная 3, родная 3, уют 3, шум 3, атмосфера 2, веселая 2, гостеприимство 2, душевная 2, спокойствие 2, счастье 2, эстетика 2, багатогранна 1, бежевый 1, безумный 1, бурлящая 1, быстроизменяющаяся 1, весело 1, возможности 1, желтый 1 , загадочная 1, габариты 1, гармонія 1, гомінна 1, домашняя 1, запоминающаяся 1, емоиійна 1, интересная 1, колорит 1 , красиво 1, легендарная 1, людная 1, масштабная 1, многолюдная 1, оранжевый 1, открытая 1, позитив 1, светлая 1, синий 1, старинная 1, умиротворенность 1, шарм 1, шумная 1, яркая жизнь 1. Таким образом, было обнаружено 13,4\% словассоциаций, описывающих город.

В описании города Одесса распространенными реакциями жителей являются связанные с юмором и празником $(7,1 \%$ всех реакций): юмор 18, смех 7, веселье 3, анекдоть 1, артист 1, кино 1, музыка 1, праздник 1, одесские шутки 1, одесский колорит 1, талант 1, творчество 1, уличные музыканты 1, хороший юмор 1, юморина 1, юморная 1 , ярмарка 1 .

Типичными реакциями на слово «Одесса» являются имеющие символическое выражение в сознании жителей города, что может быть описано такими образными 
ассоциациями: мама 7, евреи 4, акация 3, коты 2, жемчужина 1, жемчужина у моря 1, тельняшка 1,полосате майки 1, полосатая одежда 1, якорек 1.

Итогом проведенного исследования было описание психолингвистических значений «Одесса».

Одесса (117 исп.). Результаты семантической интерпретации результатов эксперимента. Концепт «ОДЕССА» ассоциируется с:

1. MOPEM 98;

2. СОЛНЦЕМ 20;

3. ЮМОРОМ 20, а также со смехом (7), весельем (3), анекдотами (1) праздником (1) юмора - юмориной (1);

4. с отдельными территориальными локациями и достопримечательностями города: ПРИВОЗ (14), ПЛЯЖ (15), ДОМ (10), ДЕРИБАСОВСКАЯ (9), ОПЕРНЫЙ ТЕАТР (12), 7 КМ (5), ДЮК (5) и др.;

Обсуждение. Результаты нашего исследования раскрывают психолингвистическое значение концепта «Одесса» с помощью ассоциаций, представленных несколькими условными семантическими группами: «море», «юмор», «достопримечательности». Содержательный и количественный анализ ассоциатов полученных семантических групп позволяет определить Одессу в языковом сознании ее жителей как морской туристический город, имеющий славную историю, красивую архитектуру и являющийся символом юмора.

В отличие от других больших городов постсоветского пространства, Одесса не обладает ассоциативными признаками города-мегаполиса в языковом сознании одесситов. Например, в исследовании Н.Г. Кудрявцевой (2006) показано большую частоту ассоциатов «мегаполис», «огромная», «большая», «грязь», «загазованный воздух» к слову-стимулу «Москва». Эти ассоциаты, по данным Н.Г. Кудрявцевой (2006), не свойственны слову-стимулу «Киев» и «Симферополь», и по нашим данным слову-стимулу «Одесса». Кроме того, в нашем исследовании не были обнаружены ассоциации, указывающие на Одессу как на научный и промышленный центр с большой инфраструктурой. 
Самыми распространенными ассоциатами этой тематики выступили разве что «портовый город» (1) и «морской вокзал» (1). Таким образом, концепт «Одесса» в отличие от концептов «Москва» и «Киев» не ассоциируется с тематикой большого города-мегаполиса с развитой инфраструктурой.

Н.Г. Кудрявцевой также показано, что слово-стимул «Киев» наиболее часто ассоциируется у его жителей с его достопримечательностями (Крещатик, Майдан Незалежности, Андреевский спуск, Софиевский собор, Владимирский собор, Золотые ворота и т.д.), с историческими событиями и личностями (Богдан Хмельницкий, Оранжевая революция и др.) как и слово-стимул «Москва» у москвичей (ВДНХ, Кремль, Третьяковская галерея, куранты, древность, златоглавая и т.д.). В нашем исследовании также показано высокий процент ассоциаций, раскрывающих историю и достопримечательности города Одессы, что может свидетельствовать о склонности одесситов как жителей красивого города с большой историей описывать его через исторические и знаковые места.

По данным уже упомянутого исследования Н.Г. Кудрявцевой (2006), среди ассоциатов концепта «Киев» отмечена высокая доля слов «каштаны» и «Як тебе не любити, Києве мій!» (прецедентный текст - слова из одноименной песни), а для концепта «Москва» были получены ассоциации «Дорогая моя столица, дорогая моя Москва!» (слова из песни «Моя Москва»). В нашем исследовании также отмечены прецедентные ассоциации: «шаланды полные кефали» и «жемчужина у моря» из одноименных песен М.Е. Табачникова встречаются в ассоциативном поле изученного нами концепта.

Выводы. Из результатов семантической интерпретации концепта «Одесса» следует, что этот город ассоциируется у его жителей с морем, красивой архитектурой и славной историей, отождествляется с юмориной и весельем. В ассоциативном поле данного концепта наибольшую группу ассоциатов составили те, которые описывают его связь с природой и морем. Значительную группу периферийных и единичных реакций составили лексемы, относящиеся к ассоциативному полю 
архитектурной и исторической тематики.

\section{Литература}

Киселева, Е. А. (2009). Опыт экспериментального психолингвистического исследования образов России и Японии в обыденном сознании студентов Новосибирского государственного университета. Вестник Новосибирского государственного университета. Сер. Лингвистика и межкультурная коммуникация. 7 (2). С. 103-115.

Колесова, И. Е., Ганичева, С. А. (2016). Образ Вологды в языковой картине мира студентов и школьников. Актуальные проблемь обучения русскому языку ХII: Mатериаль международной конференции / Ed. Anastasia Sokolova. Masarykova univerzita Pedagogická fakulta. Brno: Masarykova univerzita, C. 179-184.

Кудрявцева, Н. Г. (2006). Ассоциативное поле концепта столица в сознании носителей русского языка. Ученые записки института им. В.И. Вернадского. Серия «Филология». 19 (58). C. 121-127.

Кулик, Д. П. (2012). Образ Франции в языковом сознании сибирских студентов (на материале психолингвистического эксперимента). Молодёжь и наука: Сборник материалов VIII Всероссийской научно-технической конференции студентов, аспирантов и молодых учёных, посвященной 155-летию со дня рождения К.Э. Циолковского. Красноярск: Сибирский федеральный ун-т, 2012. URL: http://conf.sfu-kras.ru/sites/mn2012/section28.html

Петухова, В., Наумова, Н. Г. (2014). Объективация концепта «Америка» в языковом сознании современной молодежи. Проблемы языковой картины мира в синхронии и диахронии: сборник материалов Всероссийской конференции молодых ученых. Нижний Новгород: НГПУ, С. 18-24.
Стернин,
И. А.,
Рудакова,
A. B.
(2012).

Психолингвистическое значение и его описание. Теоретические проблемы. LAP Lambert Academic Publishing" Saarbrücken. 
Стернин, И. А., Саломатина, М. С. (2011). Семантический анализ слова в контексте. Воронеж: «Истоки», $150 \mathrm{c}$.

Тарасов, Е.Ф. (2006). Образ России: методология исследования. Вопросы психолингвистики. 4. С. 69-73.

Фельде, О. В. (2011). Свои и чужие в языковом сознании сибиряков. Вестник Томского государственного университета. Сер. Филология. 3(15). С. 59-64.

Чесноков, И. И. (2003). Концепт ЕВРОПА в языковом сознании российских студентов. Вестник Волгоградского государственного университета. Сер. 2: Языкознание. № 3. C. 69-72.

Ши, Ся. (2008). Концепт КИТАЙ в русском обыденном языковом сознании: дисс. ...канд. филол. наук: 10.02.01 / ФГОУ ВПО «Московский государственный университет имени М.В. Ломоносова». Москва, 209 с.

Kondratyeva O., \& Frolova T. (2018). The Image of Region in Ordinary Language Consciousness of its Residents (on an Example of an Image of Kuzbass). PSYCHOLINGUISTICS, 24(2), 78-96. URL: https://doi.org/10.31470/2309-1797-2018-24-2-78-96.

Kudryavtsev K. (2019). Psychosemantics of the image of a megapolis city. Вісник ХНПУ імені Г.С. Сковороди. Психологія. Вип. 60. Х.: ХНПУ.С. 126-140.

Орихінальний рукопис отриманий 22 травня 2019 року

Стаття прийнята до друку 31 травня 2019 року 